\title{
Novel ceramic processing method for substitution of toxic plasticizers
}

\author{
*S. Foghmoes, F. Teocoli, K. Brodersen, ${ }^{\dagger}$ T. Klemensø and M. Della Negra \\ Department of Energy Conversion and Storage, Technical University of Denmark, \\ Frederiksborgvej 399, DK-4000 Roskilde, Denmark
}

\begin{abstract}
A systematic screening of plasticisers for a polyvinyl butyral based binder system revealed that dibutyl maleate, dibutyl adipate and Pycal 94 are promising and less toxic alternatives to the very harmful but frequently used dibutyl phthalate. Pycal 94 seems especially promising as it unlike the two other candidates did not require a co-plasticiser, such as a polyethylene glycol, thus simplifying the system and reducing the risk of unwanted crossinteractions.

An effective and systematic procedure for substitution of the plasticiser, while maintaining chemical compatibility and mechanical properties, was also demonstrated. Incompatible systems were discarded in an initial broad screening while primary systems were further evaluated based on debinding properties, mechanical properties, flow behavior as well as sintering properties of ceramic tapes. The thermomechanical characterization performed on dried drops of binder and their corresponding tapes show strong similarities in the strain/stress profiles, validating the qualitative method used.
\end{abstract}

Keywords

Ceramic processing; slurry formulation, plasticizers, toxicity, binder systems

1. Introduction

For non-aqueous binder systems for tape casting, polyvinyl butyral (PVB) is a common binder [1], [2], [3], [4] and [5], and it forms a network based on hydrogen bonding which acts as a matrix for the ceramic particles [3] and [4]. A PVB based system is ascribed a

\footnotetext{
Corresponding author, Tel.: +45 4677 5689; fax: +45 4677 5858. E-mail address: safo@dtu.dk

† Present address: Høiberg A/S, St. Kongensgade 59 A, 1264 Copenhagen K, Denmark
} 
number of beneficial properties including high green strength, good flow properties, solubility in many common non-aqueous solvents, compatibility with other additives as well as a stabilizing effect on ceramic suspensions [4]. The length of the PVB chain determines the mechanical properties in the green state and it has been shown that an increased molecular weight of the PVB binder will result in increased green strength at the expense of plasticity [1].

In order to add an adequate plasticity to a PVB based binder system, an ortho-phthalate plasticizer is the common choice for non-aqueous processing [5]. The plasticizer acts by reducing the attractive forces between nearby binder chains and prevents the formation of stiff and brittle green ceramics [3]. The plasticizer will in general reduce the strength while improving the flexibility and decreasing the elastic modulus, internal stresses and the glass transition temperature in the green state [3], [4], [5], [6]. The properties are often enhanced with increasing amounts and Pradhan et al. [10] has shown a decreased transition temperature with increasing plasticizer amounts.

The efficiency of the plasticizer will in general depend on the size and the active groups, and a plasticizer with a low molecular weight and few active groups is in general more efficient. This effect is achieved through a high mobility [3], [4] though the effect can be lost if the plasticizer is too small compared to the binder [6]. The effect will also be lost if the active groups cross-link with the binder, causing stiffening and strengthening of the binder network [6].

Ortho-phthalates have been shown to be very efficient, when compared to aliphatic linear structures for PVB based binder systems, and this is ascribed to the aromatic unit [3]. Ortho-phthalates have however recently become unwanted as some of them exhibit a number of unwanted health effects including possible damage to unborn children, high toxicity to aquatic life as well as suspected damages to fertility. Dihexyl phthalate, dipentyl phthalate (DPP), N-pentyl-isopentyl phthalate, diisopentyl phthalate, bis(2-methoxyethyl) phthalate, diisobutyl phthalate (DIBP), Benzyl butyl phthalate (BBP), bis(2-ethylhexyl) phthalate (DEHP) and dibutyl phthalate (DBP) have all been included on the European Chemicals Agency's "Candidate List of substances of very high concern for authorisation" with the reason "Toxic for reproduction" [7]. The latter four also appears on the "Authorization List" [8] while dihexyl phthalate is on the "Recommendation for inclusion in the Authorisation List" [9]. It is hence desirable to replace ortho-phthalates with other 
components even though it may affect lamination properties and microstructure [4], [10], [11].

Typically azeotropic solvent mixtures such as toluene-ethanol, xylene-ethanol or 2butanone-ethanol are investigated for binder systems and tape casting slurries [12] due to beneficial properties such as solubility, dielectric constant and evaporation rate [13], [14]. Pure ethanol is however much more desirable from a handling and health perspective.

Recent investigations have shown viable alternatives to ortho-phthalates such as a modified castor oil [15] and triethylene glycol di-2-ethylhexanoate (S-2075) [16]. The present work aims at identifying additional plasticizers which are compatible with a PVB based binder system with ethanol as the sole solvent. Specifically dibutyl maleate, dibutyl adipate, Pycal 94, Hexamoll Dinch, tris(2-ethylhexyl) trimellitate and bis(2-ethylhexyl) terephthalate (a para-phthalate) was investigated both with and without a polyethylene glycol (PEG) as a co-plasticizer.

Incompatible systems were discarded in an initial broad screening while primary candidate systems were evaluated based on debinding properties, mechanical properties, flow behaviour as well as on sintering properties. The applicability of the systems, and thereby also of the more general substitution methodology, was demonstrated on a tape cast 8YSZ (8 mol\% $\mathrm{Y}_{2} \mathrm{O}_{3}$ stabilized $\mathrm{ZrO}_{2}$ ) electrolyte layer for use in an electrolyte supported solid oxide fuel cell.

\section{Experimental procedure}

\subsection{Materials}

The powder used was TZ8Y from TOSOH while the solvent was $99.9 \%$ ethanol from CCS Healthcare.

For the binder and dispersant a PVB and polyvinyl pyrrolidone (PVP) polymer were used respectively [17]. Figure 1 gives structures and additional specifications.
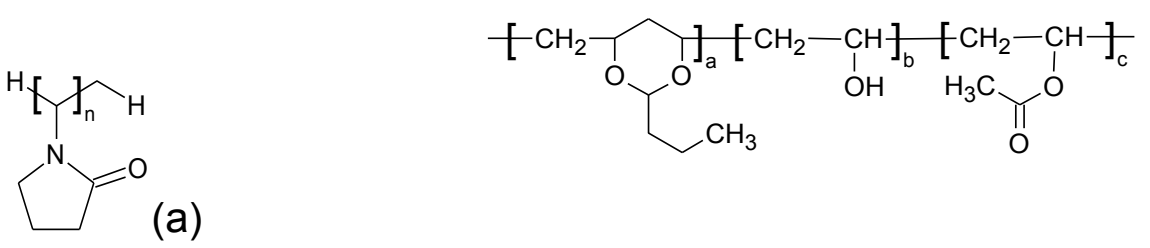

(a) 
Figure 1: Chemical structures, names and additional specifications for (a) polyvinyl pyrrolidone and (b) the binder. For the binder $a=78.0 \pm 3.0 \mathrm{~mol} \%$, $\mathrm{b}=19.5 \pm 1.5 \mathrm{~mol} \%$ and $\mathrm{c}=2.5 \pm 1.5 \mathrm{~mol} \%$

As plasticisers the following were obtained from Sigma-Aldrich: Polyethylene glycol (PEG $600)$, tris(2-ethylhexyl) trimellitate (99\%), bis(2-ethylhexyl) terephthalate ( $\geq 96 \%)$, dibutyl adipate (96\%), dibutyl maleate (96\%). Additionally 1,2 cyclohexane dicarboxylic acid diisonyl ester (Hexamoll Dinch) from BASF, Pycal 94 from Tape Casting Warehouse and dibutyl phthalate (for synthesis) from Merck were used. The dibutyl phthalate is included as a reference. The structures of all plasticisers but Pycal 94 were given by the supplier and can be seen in figure 2 .

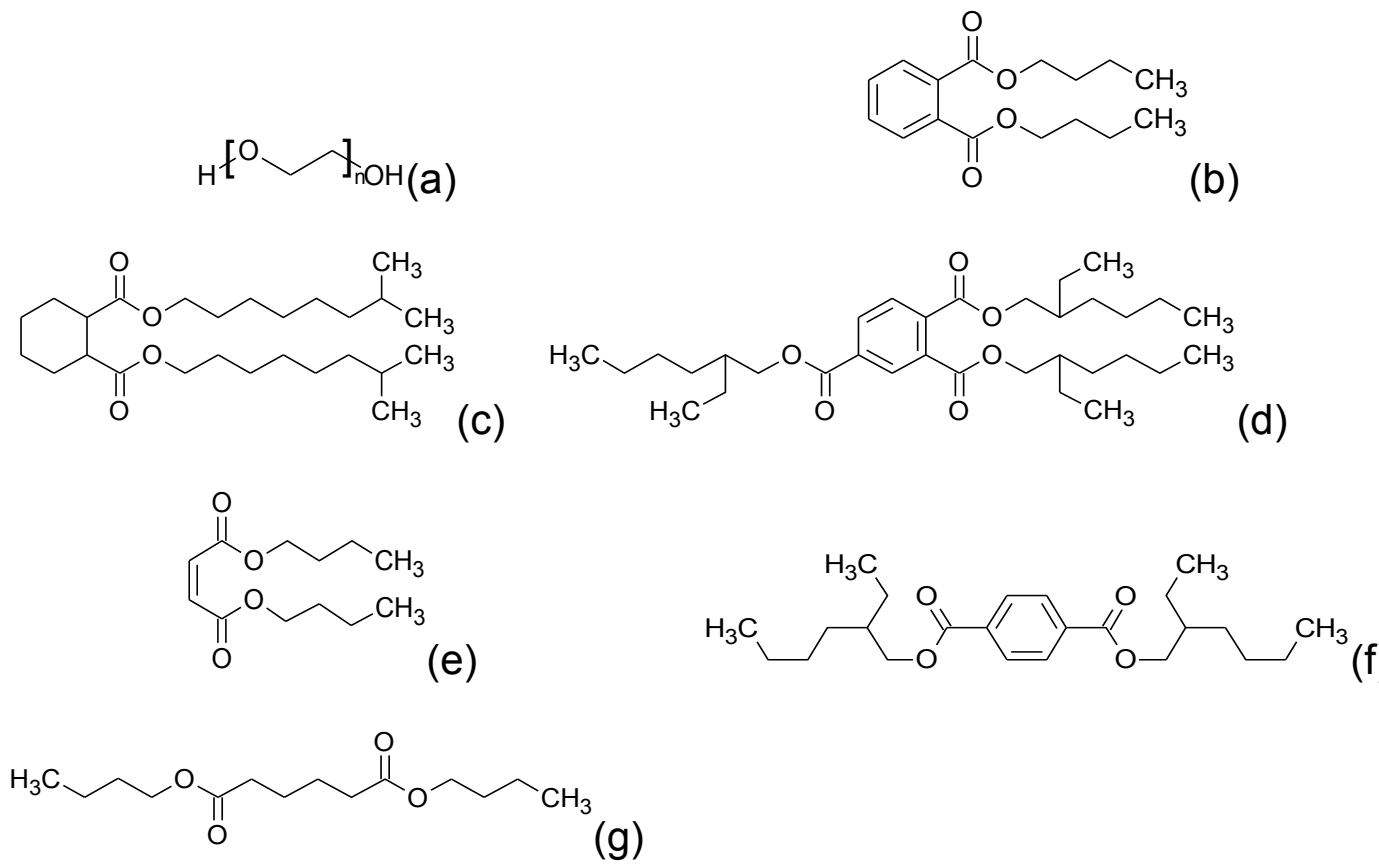

Figure 2: Chemical structures and names of (a) polyethylene glycol, (b) dibutyl phthalate, (c) 1,2 cyclohexane dicarboxylic acid diisonyl ester, (d) tris(2-ethylhexyl) trimellitate, (e) dibutyl maleate, (f) bis(2ethylhexyl) terephthalate and (g) dibutyl adipate

Pycal 94 has previously been identified as a polyoxyethylene aryl ether [18] but the specific structure has not been disclosed.

\subsection{Selection and preparation of plasticizer systems}


The variety of plasticisers was chosen in order to screen a broad spectrum of alternatives to DBP including different positions and lengths of the functional groups as well as different rigidities of the overall molecules. The dibutyl adipate is a small molecule with free rotation around all carbon bonds and with small functional groups, while tris(2-ethylhexyl) trimellitate is a much more rigid molecule, due to the stiff aromatic ring, with much bigger functional groups.

The total amount of plasticisers as well as the number of possible combinations made some initial rough screenings of suitable systems necessary.

It was decided to use a two component plasticizer system with a PEG as co-plasticiser. The use of a co-plasticiser can be desirable as different classes of plasticisers acts differently and induce slightly different behaviours to the final green tape [19] and [20]. PEG 600 was selected as initial mixtures indicated increased sweating, when using shorter and more mobile PEGs, and as long chained PEGs has previously been described as unfavourable [4].

An overall composition with $20 \%$ binder, $20 \%$ total plasticizer and $60 \%$ solvent was used as initial screenings showed suitable viscosities for most mixtures at these ratios. The chosen ratio also allows for a suitable ceramic content of approx. $43 \mathrm{vol} . \%$ in the dried tape with slight variations depending on the specific plasticiser(s) used. The ratio between the two plasticisers was varied between the pure PEG 600 to the other pure end component with intermediate steps at a 75:25, 50:50 and 25:75 ratios.

The binder systems were prepared by first mixing bigger batches of the PVB binder in ethanol and then subsequently mixing the plasticisers with parts of these base mixtures. This was done in order to have a more constant binder loading in all mixtures.

A base mixture was prepared by dissolving $200 \mathrm{~g}$ of PVB with $600 \mathrm{~g}$ of ethanol in a $2 \mathrm{~L}$ PE-bottle for $24 \mathrm{~h}$ at approximately $100 \mathrm{rpm}$. $40 \mathrm{~g}$ of this mixture was subsequently transferred into a $100 \mathrm{ml} \mathrm{PE-bottle} \mathrm{and} \mathrm{mixed} \mathrm{with} 10 \mathrm{~g}$ of plasticiser(s) for another $24 \mathrm{~h}$ at $100 \mathrm{rpm}$. The samples were visually inspected for homogeneity after each step.

For a few selected systems the binder to plasticiser ratio was additionally varied in order to obtain slightly better flow properties. This was done by varying the amount of plasticisers added to the base mixture in the second mixing step.

After the above preparation the mixtures were poured onto a tape casting carrier foil and allowed to dry for at least 24 hours. Samples showing good chemical compatibility as well as mechanical properties similar to the reference were selected as primary candidates for 
further testing. As a reference a DBP based system with a 50:50 DBP:PEG 600 ratio was used. This is similar to the systems used by Raeder et al [17].

\subsection{Thermogravimetric analysis on binder droplets}

Thermogravimetric (TG) measurements were performed using a Netzsch STA 409 CD with an alumina crucible in a flow of air set to $50 \mathrm{ml} / \mathrm{min}$. Heating ramps were set to 0.25 ${ }^{\circ} \mathrm{C} / \mathrm{min}$ from $20-700{ }^{\circ} \mathrm{C}$ followed by cooling ramps set to $2.0^{\circ} \mathrm{C} / \mathrm{min}$ down to $25^{\circ} \mathrm{C}$. About $100 \mathrm{mg}$ of sample were used for each measurement.

\subsection{Rheology}

Flow curves are obtained using a controlled shear rate test (CR). Rheological data was collected using a Haake RheoStress 600 rheometer (Thermo Electron $\mathrm{GmbH}$ ) equipped with a DC30 temperature control unit operating at $21^{\circ} \mathrm{C}$. A $60 \mathrm{~mm}$ parallel plate geometry with a $0.8 \mathrm{~mm}$ gap was used. The following measuring protocol was selected: $0.1-501 / \mathrm{s}$ and $50-0.1 \frac{1}{\mathrm{~s}}$ over $100 \mathrm{sec}$. with a pre-shear of $5 \frac{1}{\mathrm{~s}}$ and $0.1 \frac{1}{\mathrm{~s}}$ for $30 \mathrm{sec}$.

A viscosity range of $3000 \mathrm{mPa} \cdot \mathrm{s} \pm 500 \mathrm{mPa} \cdot \mathrm{s}$ at a shear rate of $101 / \mathrm{s}$ was considered acceptable for the final tapes.

\subsection{Particle sizing}

A Beckman Coulter LS 13320 with a measurement range of $0.04-2000 \mu \mathrm{m}$ was used to analyse the particle size distributions before and after binder addition in order to ensure that the selected binder system does not affect the slurry stability. All particle size distributions were evaluated using at least 3 samplings to ensure good data quality. The effect of different obscurations was used to assess different sensitivities at different size ranges [21].

\subsection{Thermomechanical analysis on tapes and binder droplets}

For thermomechanical analysis (TMA) a Netzsch TMA 402 F1 Hyperion was used for a quantitative analysis of the strength of 8YSZ based tapes prepared using selected binder systems. The tape segments were analysed using tension mode and had a length of approx. $7.25 \mathrm{~mm}$, a width of approx. $2.25 \mathrm{~mm}$ and a thickness of approx. $170 \mu \mathrm{m}$. The 
temperature was adjusted to $25{ }^{\circ} \mathrm{C}$ in a nitrogen atmosphere and the applied force was then ramped to $3 \mathrm{~N}$ over 5 hours using a constant rate.

For measurements on pure binder mixtures the same measuring protocol was used. The droplets were produced using a deaired binder and a hand operated doctor blade with a height of $1000 \mu \mathrm{m}$. This route was applied in order to eliminate some of the inherent errors associated with the crude initial screening described in a previous section.

Young's modulus was calculated as the slope of the initial straight part of a stress-stain curve. The reported elongation brake and tensile strength is given by the last recorded point before sample rupture and is therefore a lower estimate.

\subsection{Tape casting, sintering and post examination}

The tape casting slurries were prepared by dissolving $6.7 \mathrm{~g}$ of dispersant in $78.5 \mathrm{~g}$ of ethanol in a $1 \mathrm{~L}$ PE bottle. Upon dissolving the dispersant $150 \mathrm{~g}$ of TZ8Y was then added and the slurry was milled for 3 days at approx. $200 \mathrm{rpm}$ using $1 \mathrm{~kg}$ of $3 / 8$ inch zirconia milling beads. $74.7 \mathrm{~g}$ of a premixed binder system was then added and mixed in over the following 24 hours. The binders were mixed according to the ratios later identified as primary candidates.

The slurries were filtered using a $37 \mu \mathrm{m}$ filter and de-aired prior to tape casting.

A double doctor-blade system was used for tape casting with a casting gap of $1000 \mu \mathrm{m}$ and the tapes were allowed to dry at slow ventilation overnight inside the tape caster before further handling.

Four samples with a diameter of $40 \mathrm{~mm}$ were stamped out of each tape and sintered.

In order to ensure a slow debinding, the samples were slowly heated with $0.25{ }^{\circ} \mathrm{C} / \mathrm{min}$ to $600{ }^{\circ} \mathrm{C}$ followed by a binder burnout for 4 hours at $600{ }^{\circ} \mathrm{C}$. The samples were then heated with $1{ }^{\circ} \mathrm{C} / \mathrm{min}$ to $1255^{\circ} \mathrm{C}$ followed by a sintering for 12 hours at $1255^{\circ} \mathrm{C}$. The samples were finally cooled to room temperature with $100^{\circ} \mathrm{C} / \mathrm{h}$.

The sintered samples were mounted in epoxy and polished until a $1 / 4$ micron diamond suspension for investigation with a Hitachi TM1000 microscope, using a solid state backscattered electron detector, to assess the microstructure of the sintered samples.

3. Assessment of environmental and health impact of the selected plasticizers 
To avoid replacing the toxic ortho-phthalates with other toxic chemicals some effort was used to assess possible environmental and health issues with the chemicals proposed.

An initial evaluation of the material safety data sheet (MSDS) of the used plasticisers reveals much favourable properties when compared to DBP. The MSDS of dibutyl maleate indicates problems with skin and eye sensitisation. The remaining plasticisers are classified as "not a hazardous substance or mixture according to Regulation (EC) No. 1272/2008" and "not a hazardous substance or mixture according to EC-directives $67 / 548 /$ EEC or 1999/45/EC".

However, regarding bis(2-ethylhexyl) terephthalate and Hexamoll Dinch, a comprehensive independent study has been found indicating both subchronic toxicity, persistence and bioaccumulation for both chemicals [22]. Regarding aquatic toxicity bis(2-ethylhexyl) terephthalate could not be evaluated with present data while Hexamoll Dinch showed no issues.

All in all, the selected plasticisers are considered as less toxic alternatives to orthophthalates although the amount of literature is very limited compared to that regarding ortho-phthalates.

\section{Results and discussion}

The prepared model samples of the binder systems were, for the initial rough screening, evaluated by the qualitative measures: strong $(S)$, weak $(W)$, flexible $(F)$, inflexible $(I)$, opaque (O) and sweating (SW). Opaqueness and sweating did in many cases occur at the same time and often weak or sweating binders will have some stickiness. A few examples are shown in the pictures presented in figure 3.

(a)

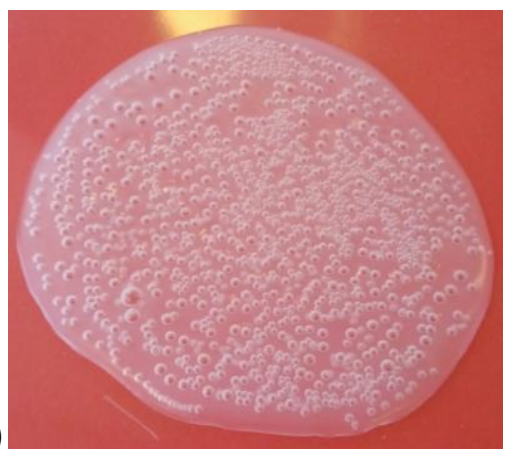

(b)

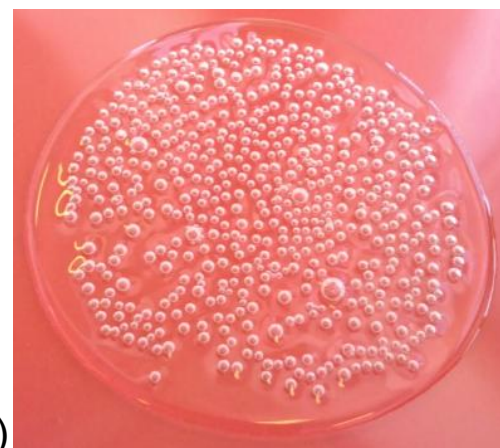

(c)

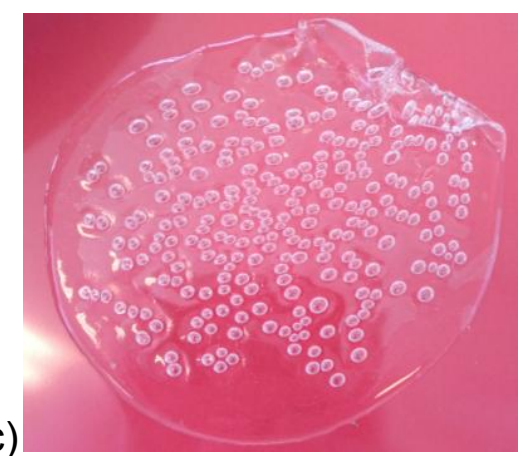

Figure 3: Pictures of dried binder droplets without de-airing illustrating (a) a very inflexible and strong binder with lack of transparency due to binder recrystallization, (b) a suitable 
binder composition and (c) a weak and very flexible binder being so sticky that it can glue to itself.

This very visual and qualitative initial characterization is similar to the one reported by Schafbauer et al. for optimizing the binder content in slurries for tape casting formulations [23]

For Hexamoll Dinch, tris(2-ethylhexyl) trimellitate and bis(2-ethylhexyl) terephthalate all of the tested binder mixtures showed signs of sweating or had an opaque appearance. The sweating is believed to be due to an exsolution of excess plasticiser while the opaque appearance is believed to be due to a recrystallization of excess binder both indicating an unwanted poor chemical compatibility of the plasticiser with a PVB and ethanol system. These plasticisers were additionally exhibiting very little plasticity and they were thus discarded from further testing. The little plasticity added by these more bulky and stiff molecules seems consistent with earlier reports recommending plasticisers with low molecular weight and few active groups due to the higher mobility [3], [4].

For dibutyl maleate, dibutyl adipate and Pycal 94 at least one composition showed good chemical compatibility, indicated by no sweating or opaqueness, as well as a mechanical properties roughly comparable to the reference system as seen from figure 4.

Figure 4 shows the compositions of the model samples, and the qualitative evaluation is indicated next to the composition. The one or two compositions showing good chemical compatibility, observed through lack of sweating and opaqueness, as well as a strength and flexibility similar to the phthalate based reference, are marked as "primary candidate" and "secondary candidate", respectively.

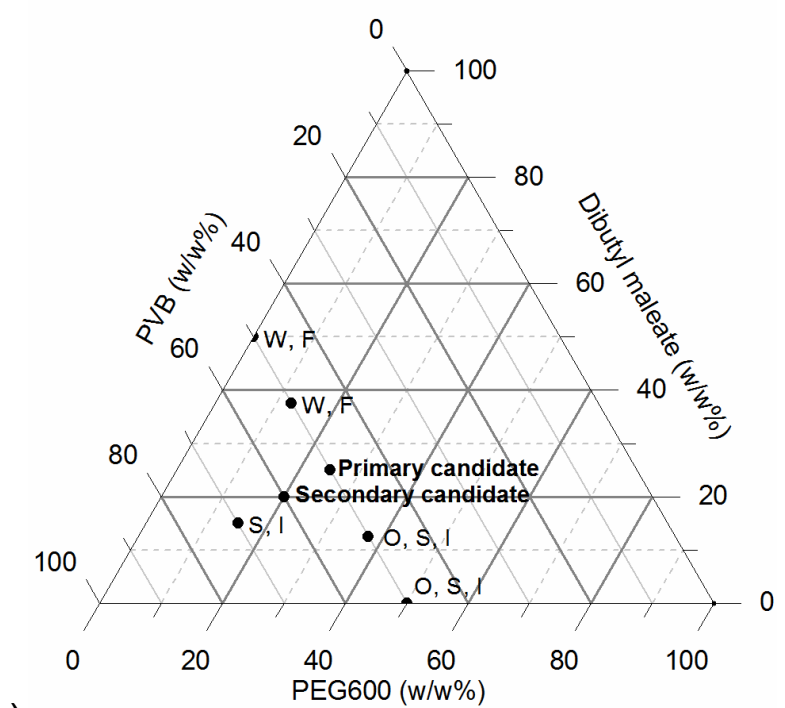

(a)

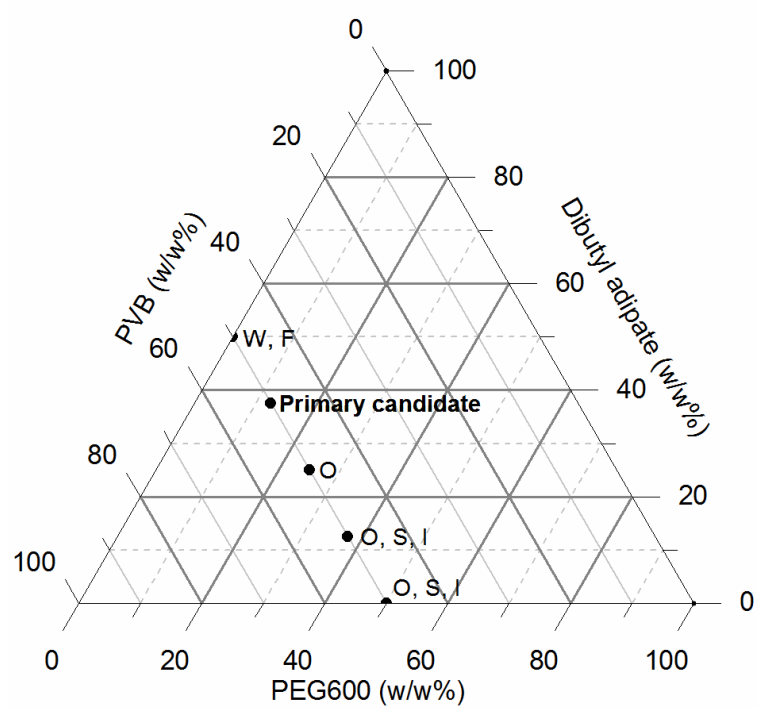

(b) 


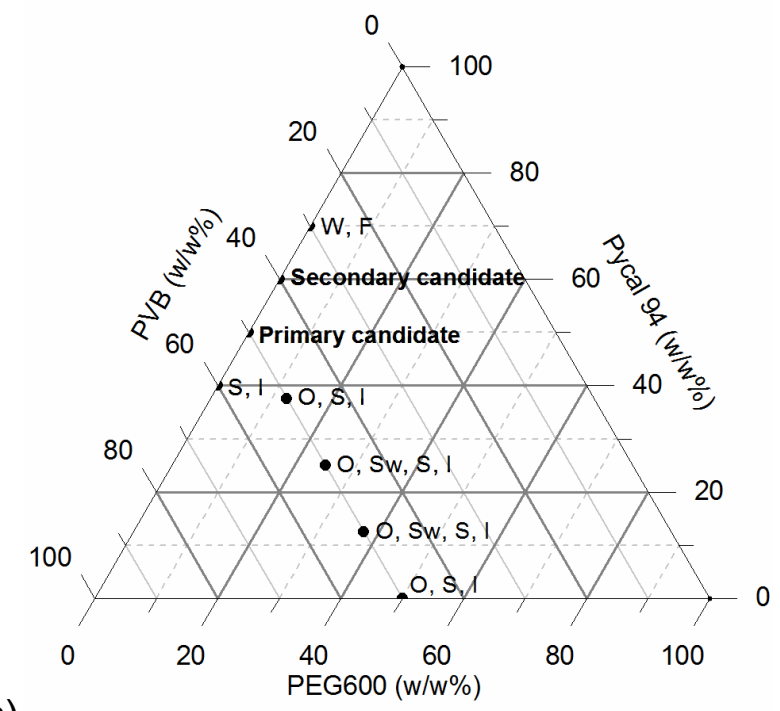

(c)

Figure 4: Plot of tested compositions for (a) dibutyl maleate, (b) dibutyl adipate and (c) Pycal 94 with $\mathrm{W}=$ Weak, $\mathrm{F}=$ Flexible, $\mathrm{S}=$ Strong, $\mathrm{I}=$ Inflexible, $\mathrm{O}=$ Opaque and $\mathrm{Sw}=$ Sweating

The PEG 600 rich compositions all appeared opaque with little plasticity. For Pycal 94 a PEG 600 free system is preferred whereas both the dibutyl adipate and dibutyl maleate based systems require addition of some PEG 600 for maintaining adequate strength. The consistent opaqueness and sweating at high PEG 600 loadings suggests limited compatibility between PEG 600 and PVB while the lack of plasticity is consistent with the earlier reported preference for plasticisers with a low molecular weight and few active groups [3], [4]. The location of the optimal compositions can be seen in figure 5.

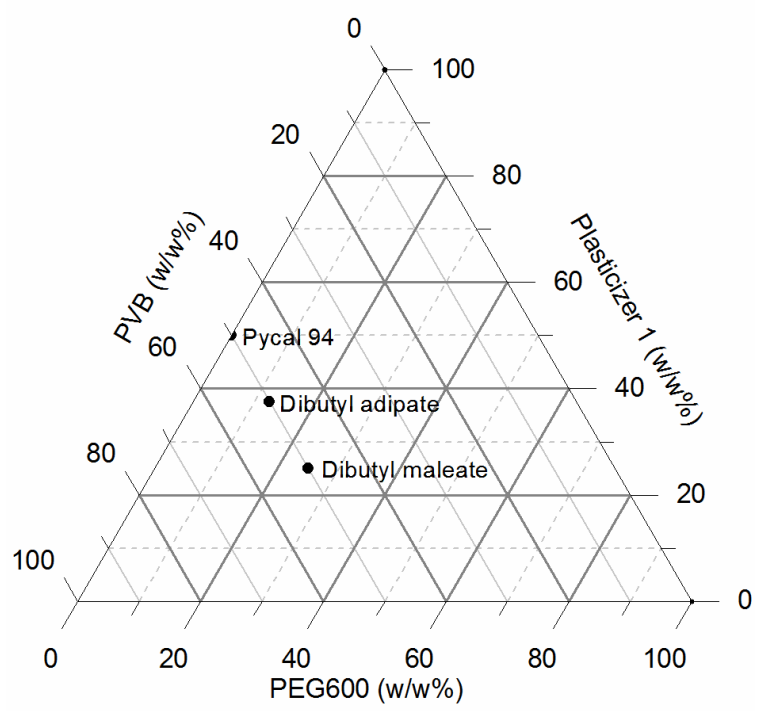

Figure 5: Plot of the optimum composition for the best candidates. 
A region around the 3 compositions marked in figure 5 could likely be a general region for other plasticisers within this system considering both mechanical properties and the chemical compatibility between PEG 600 and PVB.

As shown in figure 6 the viscosity of the three candidate systems were somewhat below that of the reference system but at a level which is handable by variation of solvent addition for a tape casting slurry. All mixtures show a slight shear thinning behaviour which is favourable during the tape casting process.

The shear thinning effect is desirable during tape casting as it ensures a low viscosity during passage of the narrow gap under the doctor-blade(s), allowing for a good uniform coverage, and a high viscosity in the casting tray and in the deposited film thus preventing sedimentation and stabilizing the final shape.

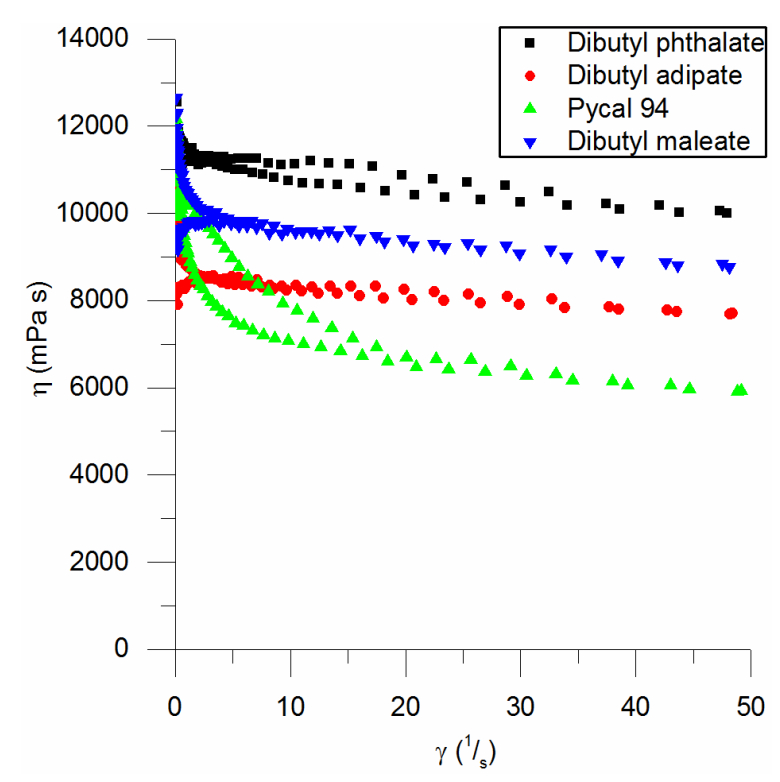

Figure 6: Plot of the viscosity $(\eta)$ as a function of sheer rate $(\gamma)$ for the best candidates with a DBP based binder system as reference

Regarding burnout properties it is advantageous to have a slow and smooth profile thus limiting the rate of gas release during binder burn-out and allowing for some necking of the ceramic particles before all the organics are gone. Looking at the TG profiles given in figure 7 the profiles are in general suitable for tape casting with the only concern being the binder system containing dibutyl adipate, which exhibits a rapid change just above $300^{\circ} \mathrm{C}$. This rapid decomposition is likely due to an unfavourable overlap of the boiling point of DBA and the auto ignition temperature of PEG 600 at $305^{\circ} \mathrm{C}$. 
The decomposition is in all cases on-setting at temperatures in excess of approx. $200{ }^{\circ} \mathrm{C}$ and all decomposition is over at around $450{ }^{\circ} \mathrm{C}$. Similar behaviour has previously been reported for comparable systems [23, 24].

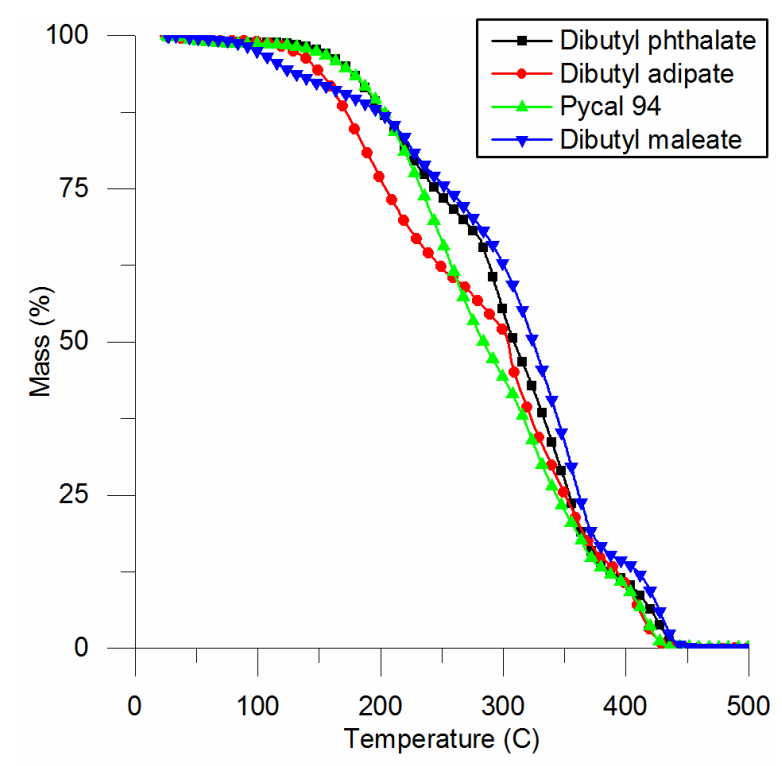

Figure 7: TG profile for the best candidates with a DBP based binder system as reference

For the optimum binder compositions, given in figure 5, tapes of about 1 meter in length were made. All tapes came out defect free with very small variations in thickness and with smooth surfaces and good releasing properties. The green thickness was measured to about $170 \mu \mathrm{m} \pm 5 \mu \mathrm{m}$ for all tapes estimated from a number of measurements points along and across the tapes.

The particle size distribution was measured before and after binder addition as shown in figure 8. This was done in order to ensure that a difference in particle size distribution would not be the origin of a possible difference in sintering properties and to ensure that none of the plasticizers has unwanted incompatibilities with the used dispersant which could for instance cause flocculation. 


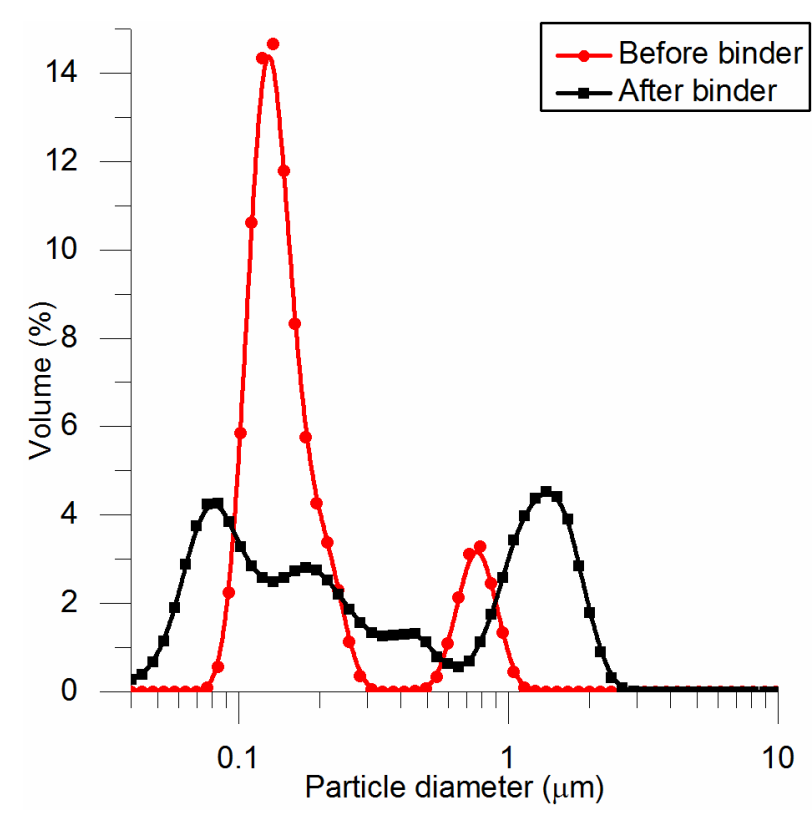

Figure 8: Typical particle size distributions for all systems before and after binder addition.

All samples have similar distributions just before and after binder addition and none of the binder systems did thus induce any severe agglomeration when compared to the DBP based system. The addition of binder in general results in a slightly larger particle fraction. As shown in figure 9 a viscosity in the range of $3100-3300 \mathrm{mPas} \cdot \mathrm{s}$ at $10 \gamma^{-1}$ is observed for dibutyl phthalate, dibutyl adipate and dibutyl maleate but for Pycal 94 a significantly lower viscosity of approximately $2500 \mathrm{mPas} \cdot \mathrm{s}$ is observed.

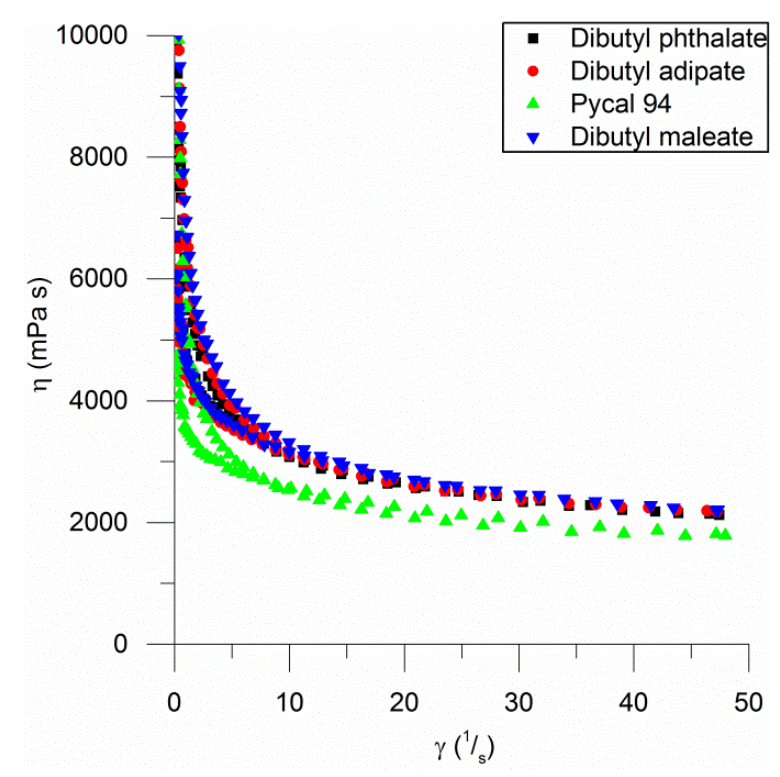

Figure 9: Plot of the viscosity $(\eta)$ as a function of shear rate $(\gamma)$ for tape casting slurries of the best candidates with a DBP based binder system as reference. 
The comparatively low viscosity of a Pycal 94 based system has previously been noted [18], and it has been suggested as an advantage, as this might allow a lowering of the solvent content.

The thermomechanical analysis performed on binder droplets and tapes reveals similar trends as seen in figure 10 with elongation brake, tensile strength and Young's modulus being reported in table 1 and table 2 .
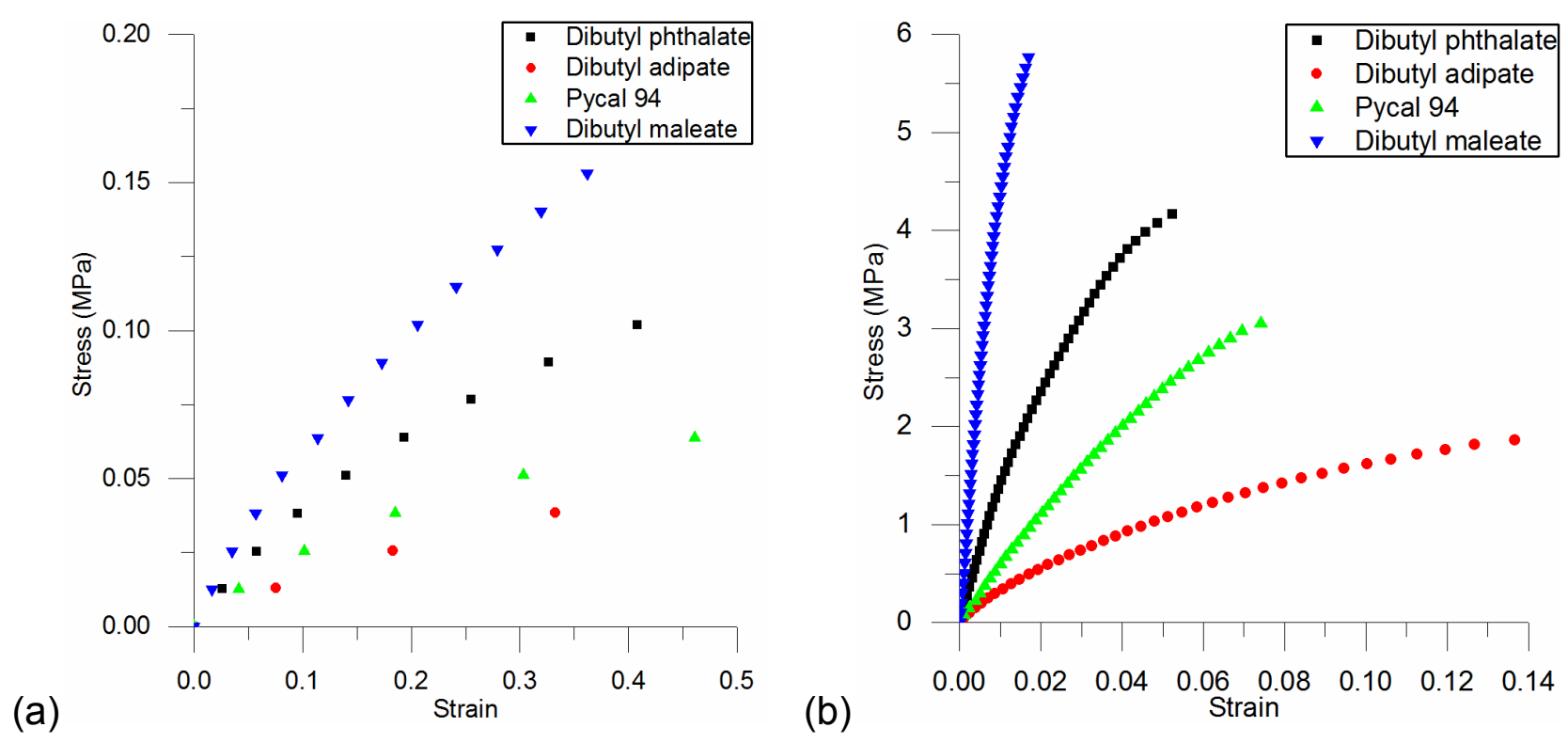

Figure 10: Stress strain profiles for a) binder droplets and b) tapes produced using the best candidates with a DBP based system as reference

\begin{tabular}{|c|c|c|c|}
\hline Plasticiser & $\begin{array}{c}\text { Elongation brake } \\
\text { (\%) }\end{array}$ & $\begin{array}{c}\text { Tensile strength } \\
\text { (MPa) }\end{array}$ & $\begin{array}{c}\text { Young's modulus } \\
\text { (MPa) }\end{array}$ \\
\hline Dibutyl phthalate & 40.8 & 0.10 & 0.42 \\
\hline Dibutyl adipate & $>33.2$ & $>0.04$ & 0.14 \\
\hline Pycal 94 & 46.1 & 0.06 & 0.26 \\
\hline Dibutyl maleate & 36.2 & 0.15 & 0.66 \\
\hline
\end{tabular}

Table 1: Elongation brake, tensile strength and Youngs Modulus for tested binder droplets

\begin{tabular}{|c|c|c|c|}
\hline Plasticiser & $\begin{array}{c}\text { Elongation brake } \\
(\%)\end{array}$ & $\begin{array}{c}\text { Tensile strength } \\
(\mathrm{MPa})\end{array}$ & $\begin{array}{c}\text { Young's modulus } \\
(\mathrm{MPa})\end{array}$ \\
\hline
\end{tabular}




\begin{tabular}{|c|c|c|c|}
\hline Dibutyl phthalate & 5.5 & 4.2 & 148 \\
\hline Dibutyl adipate & 13.7 & 1.9 & 37 \\
\hline Pycal 94 & 7.4 & 3.1 & 60 \\
\hline Dibutyl maleate & 1.8 & 5.8 & 450 \\
\hline
\end{tabular}

Table 2: Elongation brake, tensile strength and Youngs Modulus for tested tapes

The binder droplet of dibutyl adipate seems to repeatedly brake prematurely due to insignificant strength but otherwise measurements on the binder droplets reveal relevant information and trends similar to those observed in the ceramic tapes. Therefore, they could be a shortcut to get a quantitative measurement on binder strength without having to make the actual tapes. On the other hand, quantitative measurements of strength seem necessary for highlighting the large variations between the various compositions, which were not appreciated in the initial rough screening. The reason for this can be either due to a lower sensitivity in the screening phase or due to the fact that the samples used in the screening were not de-aired or cast at a specific thickness in order to save time at this initial step, which was more focused on chemical compatibility.

The strength of the tapes could be tailored by changing the plasticiser and PVB content or by selecting a PVB with a slightly different chain length but same overall chemical composition. An increase in the strength at the cost of plasticity can be achieved by increasing the PEG 600:co-plasticiser ratio or by increasing the PVB:total plasticiser ratio as demonstrated in figure 4. Alternatively the PVB chain length could be increased as previously reported [1]. As getting a PVB with the same overall chemical composition but different chain length from a commercial supplier could be difficult, the preferred choice seems to be a slight variation in the amount of added plasticisers and binder. In order to improve the strength of the rather weak dibutyl adipate based tape, it was deemed advantageous to increase the PVB content as a larger PEG 600 content would also induce opaqueness indicating poor compatibility. For the somewhat stronger Pycal 94 based tape the addition of PEG 600 would also induce opaqueness but a slightly higher PVB content could be advantageous.

For dibutyl maleate the tape seems overly strong and inflexible requiring either a reduction of the PEG 600 content or a lowering in the PVB content. Both approaches seem compatible with the compositional stability regimes found in the initial rough screening. 
Considering the overall better compatibility at lower PEG 600 loadings a reduction of the PEG 600 content is likely the more beneficial approach.

Upon sintering the produced tapes exhibited similar shrinkages (24 - 27\%) for all compositions both in the lateral dimensions $(\phi)$ as well as the thickness $(h)$ as shown in table 3.

\begin{tabular}{|c|c|c|c|c|c|c|}
\hline Plasticiser & $\begin{array}{c}\phi_{\text {before }} \\
\text { sintering }\end{array}$ & $\begin{array}{c}\phi_{\text {after }} \\
\text { sintering }\end{array}$ & $\begin{array}{c}\text { Shrinkage } \\
\boldsymbol{\phi}\end{array}$ & $\begin{array}{c}\mathbf{h}_{\text {before }} \\
\text { sintering }\end{array}$ & $\begin{array}{c}\mathbf{h}_{\text {after }} \\
\text { sintering }\end{array}$ & $\begin{array}{c}\text { Shrinkage } \\
\mathbf{h}\end{array}$ \\
\hline Dibutyl phthalate & $40.00 \mathrm{~mm}$ & $29.90 \mathrm{~mm}$ & $25.3 \%$ & $173 \mu \mathrm{m}$ & $131 \mu \mathrm{m}$ & $24.3 \%$ \\
\hline Dibutyl adipate & $40.00 \mathrm{~mm}$ & $29.65 \mathrm{~mm}$ & $25.9 \%$ & $172 \mu \mathrm{m}$ & $131 \mu \mathrm{m}$ & $23.8 \%$ \\
\hline Pycal 94 & $40.00 \mathrm{~mm}$ & $30.05 \mathrm{~mm}$ & $24.9 \%$ & $170 \mu \mathrm{m}$ & $130 \mu \mathrm{m}$ & $23.5 \%$ \\
\hline Dibutyl maleate & $40.00 \mathrm{~mm}$ & $29.95 \mathrm{~mm}$ & $25.1 \%$ & $168 \mu \mathrm{m}$ & $122 \mu \mathrm{m}$ & $27.3 \%$ \\
\hline
\end{tabular}

Table 3: Diameter $(\phi)$, height (h) and shrinkage of sintered pieces before and after sintering at $1255^{\circ} \mathrm{C}$.

All the samples appeared flat and semi-transparent after sintering, with the semi transparency indicating a dense microstructure. Based on the dimensions given in table 3 and assuming prefect cylindrical geometry the volume before sintering $\left(V_{l}\right)$ and the volume after sintering $\left(\mathrm{V}_{\mathrm{A}}\right)$ can be calculated. The experimental solids loading in the green tape $\left(\right.$ vol. $\left.\%_{\text {exp }}\right)$ can then be calculated as the ratio between them $\left(V_{A} / V_{l}\right)$. The corresponding theoretical solids loading (vol.\%theory) has been calculated from the mass and densities of the added components. The values are given in table 4.

\begin{tabular}{|c|c|c|c|c|}
\hline Plasticiser & $\mathbf{V}_{\mathbf{I}}$ & $\mathbf{V}_{\mathbf{A}}$ & vol.\%exp & vol.\%theory \\
\hline Dibutyl phthalate & $869.6 \mathrm{~mm}^{3}$ & $367.9 \mathrm{~mm}^{3}$ & $42.3 \%$ & $43.1 \%$ \\
\hline Dibutyl adipate & $864.6 \mathrm{~mm}^{3}$ & $361.8 \mathrm{~mm}^{3}$ & $41.8 \%$ & $42.3 \%$ \\
\hline Pycal 94 & $854.5 \mathrm{~mm}^{3}$ & $368.8 \mathrm{~mm}^{3}$ & $43.2 \%$ & $43.3 \%$ \\
\hline Dibutyl maleate & $844.5 \mathrm{~mm}^{3}$ & $343.8 \mathrm{~mm}^{3}$ & $40.7 \%$ & $42.8 \%$ \\
\hline
\end{tabular}

Table 4: Initial sample volume $\left(\mathrm{V}_{\mathrm{l}}\right)$, sample volume after sintering $\left(\mathrm{V}_{\mathrm{A}}\right)$, experimental solids loading (vol.\%exp) and theoretical solids loading (vol.\%theory) 
The in general rather good agreement between vol.\%exp and vol.\%theory suggests a good packing in the dried tapes. For dibutyl maleate the slightly bigger deviation indicates a still good, but not complete, packing in the green tape. As friction against the sintering substrate provides some in-plane shrinkage resistance the densification is realised through a larger change of the height as seen from table 3.

When comparing microstructures, obtained by electron microscopy of the sintered samples, a good densification is observed with a tendency for a little extra porosity towards the carrier foil seen at the bottom of the pictures in figure 11. However, only closed porosity appears to be present, and the layers are gas tight and therefore applicable for use as electrolyte layer in solid oxide fuel cell.
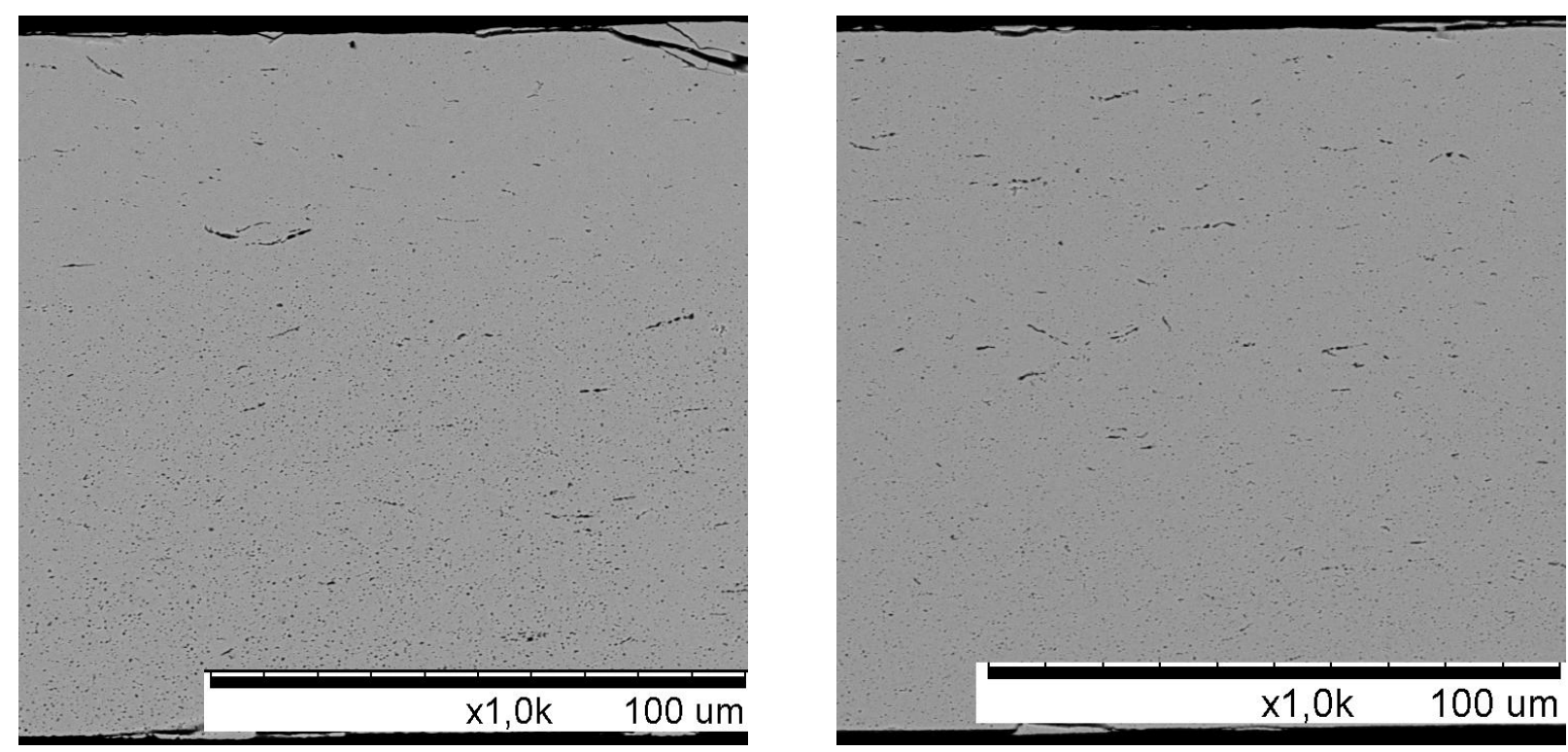

(a)

(b)
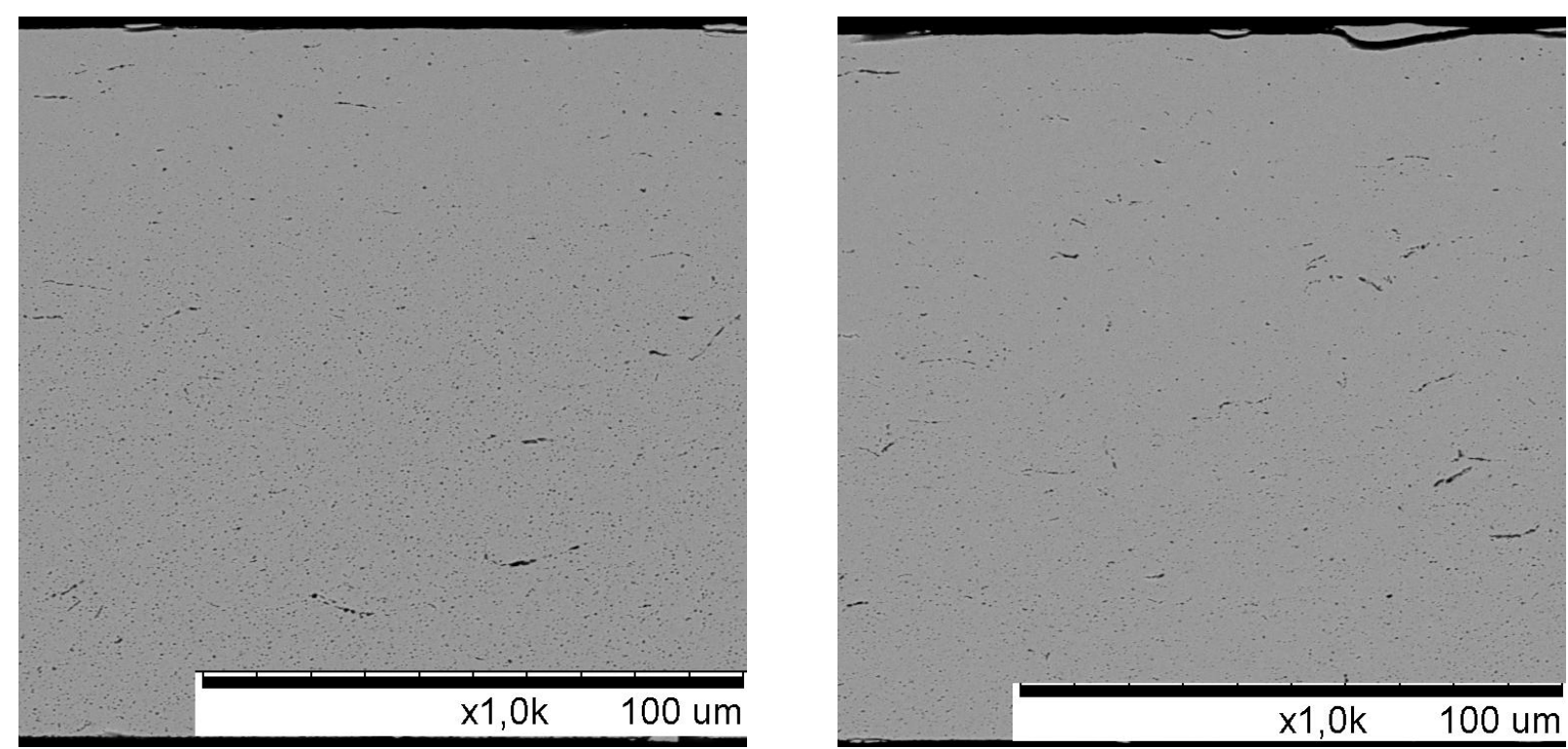

(c)

(d) 
Figure 11: Microstructure of a sample prepared with (a) the phthalate based reference binder, (b) the optimized dibutyl maleate based binder, (c) the optimized dibutyl adipate based binder and (d) the optimized Pycal 94 based binder.

The similar shrinkages, lack of curvature and crumpling and almost dense microstructures indicate that there are no significant disadvantages of using these non-phthalate binder systems and that a substitution is possible. The plasticizer substitution was demonstrated for the preparation of a dense 8YSZ layer using tape-casting but it could, however, also be expanded to be used in the preparation for other ceramic components.

The presented approach, using a qualitative screening followed by more quantitative experiments, is not limited to the substitution of toxic ortho-phthalates. It could also be used for substituting the polymeric binder or for systematically modifying the mechanical properties of an already known system giving the used method a more broad application span.

\section{Conclusions}

The presented results demonstrate a number of low toxicity plasticisers as alternatives to ortho-phthalates in a PVB and ethanol based system.

The dibutyl adipate and dibutyl maleate based systems have performances comparable to the dibutyl phthalate system, whereas, the Pycal 94 seems to be an even more promising alternative as it unlike the other candidates does not need PEG 600 as a co-plasticizer thereby simplifying the system and reducing the risk of unwanted cross-interactions. These unwanted interactions are demonstrated as sweating of plasticiser and recrystallization of binder when PEG 600 is the main or sole plasticiser added.

The paper also illustrates a systematic procedure for the substitution of one plasticiser with another resulting in good component compatibility, favourable burn-out properties and similar mechanical properties.

\section{Acknowledgements}

The work was financially supported by the Department of Energy Conversion and Storage through the SymSOEC projects. The authors acknowledge David Marhauer-Nimb for 
preparation of most binder droplets, Marianne Nielsen for tape casting and Henrik Paulsen for preparation of samples for microscopy and subsequent imaging.

Pernille Hedemark Nielsen and Carsten Gynther Sørensen are acknowledged for their assistance with the combined TG and DTA measurement.

1 Y.-S. Cho, J.-G. Yeo, Y.-G. Jung, S.-C. Choi, J. Kim, U. Paik, Effect of molecular mass of poly(vinyl butyral) and lamination pressure on the pore evolution and microstructure of $\mathrm{BaTiO}_{3}$ laminates, Mater. Sci. Eng. A 362 (2003) 174-180

2 C.-W. Cho, J.-H. Hwang, S.-C. Choi, U. Paik, M.-H. Lee, The effect of heat-treatment on the suspension stability and gelation behavior of $\mathrm{Li}_{2} \mathrm{O}-\mathrm{BaO}-\mathrm{Al}_{2} \mathrm{O}_{3}-\mathrm{SiO}_{2}-\mathrm{CaO}$ (LBASC), Mater. Chem. Phys. 99 (2006) 418-423

3 D.-H. Kim, K.-Y. Lim, U. Paik, Y.-G. Jung, Effects of chemical structure and molecular weight of plasticizer on physical properties of green tape in $\mathrm{BaTiO}_{3} / \mathrm{PVB}$ system, J. Eur. Ceram. Soc. 24 (2004) 733-738

4 K.Y. Lim, D.H. Kim, U. Paik, S.H. Kim, Effect of molecular weight of poly(ethylene glycol) on the plasticization of green sheets composed of ultrafine $\mathrm{BaTiO}_{3}$ particles and poly(vinyl butyral), Mater. Res. Bull. 38 (2003) 1021-1032

5 J.-K. Song, W.-S. Um, H.-S. Lee, M.-S. Kang, K.-W. Chung, J.-H. Park, Effect of polymer molecular weight variations on PZT slip for tape casting, J. Eur. Ceram. Soc. 20 (2000) 685-688

6 L. G. Ma, Y. Huang, J.L. Yang, H.R. Le, Y. Sun, Effect of plasticizer on the cracking of ceramic green bodies in gelcasting, J. Mater. Sci., 40 (18) (2005) 4947-4949

7 http://echa.europa.eu/web/guest/candidate-list-table

The list was last accessed $16^{\text {th }}$ of February 2016

8 http://echa.europa.eu/web/guest/addressing-chemicals-of-

concern/authorisation/recommendation-for-inclusion-in-the-authorisationlist/authorisation-list

The list was last accessed $16^{\text {th }}$ of February 2016

9 http://echa.europa.eu/web/guest/addressing-chemicals-ofconcern/authorisation/recommendation-for-inclusion-in-the-authorisation-list

The list was last accessed $16^{\text {th }}$ of February 2016

10D.K. Pradhan, B.K. Samantaray, R.N.P. Choudhary, A.K. Thakur, Effect of plasticizer on structure-property relationship in composite polymer electrolytes, J. Power Sources 139 (2005) 384-393 
11L.A. Ivanchenko, N.D. Pinchuk, A.R. Parkhomei, Effect of the plasticizer on structure formation in purified polydispersed glass ceramic composites, Glass Ceram. 64 (3-4) (2007) 136-139

12S. B. Reddy, P. P. Singh, Effect of type of solvent and dispersant on NANO PZT powder dispersion for tape casting slurry, Journal of materials Science, 37 (2002) 929-934

13Z. Jingxian, J. Dongliang, L. Weisensel, P. Greil, Binary solvent mixture for tape casting of $\mathrm{TiO}_{2}$ sheets, J. Eur. Ceram. Soc. 24 (1) (2004) 147-155

14J.-H. Feng, F. Dogan, Effects of Solvent Mixtures on Dispersion of Lanthanum-Modified Lead Zirconate Titanate Tape Casting Slurries, J. Amer. Ceram. Soc., 83 (2000) 16811686

15T. Klemensø, M. Menon, S. Ramouse, Low toxicity binder systems for tape cast $\mathrm{Ce}_{0.9} \mathrm{Gd}_{0.1} \mathrm{O}_{1.95}$ laminates, Ceramics International 36 (2010) 773-780

16R. E. Mistler, E. Bianchi, B. Wade, J. Hurlbut, Evaluation of an environmentally friendly plasticizer for polyvinyl butyral for use in tape casing. In T. Ohji, M. Singh, J. Salem and D. Zhu, editors. Advanced processing and manufacturing technologies for structural and multifunctional materials: Ceramic engineering and science procedings, volume 28. John Wiley and sons Inc., 2009, p. 27-34

17H. Raeder, C. Simon, T. Chartier, H. L. Toftegaard, Tape Casting of Zirconia for Ion Conducting Membranes: A Study of Dispersants, Journal of the European Ceramic Society, 13 (1994) 485-491

18R. E. Mistler, E. Bianchi and W. McNamee, Evaluation of Pycal 94 as an environmentally friendly plasticizer for polyvinyl butyral for use in tape casing. In $\mathrm{J}$. Matyâs, T. Ohji, X. Liu, M. P. Paranthaman, R. Devanathan, K. Fox, M. Singh and W. Wong-Ng, editors. Advances in Materials Science for Environmental and Energy Technologies II: Ceramic Transactions, Volume 241 John Wiley and sons Inc., 2013, p. 191-198

19Rodrigo Moreno, The Role of Slip Additives in Tape Casting Technology: Part II Binders and Plasticizers, American Ceramic Society bulletin, vol. 71, (1992) p. 1647 1657

20Richard E. Mistler, Eric R. Twiname, Tape casting Theorý and Practice, John Wiley \& Sons, 1. Edition March 2006

21C.M. Keck, R.H. Müller, Size analysis of submicron particles by laser diffractometry$90 \%$ of the published measurements are false, International Journal of Pharmaceutics 355 (2008), 150-163 
22J. Maag, C. Lassen, U. Brandt, J. Kjølholt, L. Molander and S. Mikkelsen

Identification and assessment of alternatives to selected phthalates.

Report by Cowi A/S for the Danish Environmental Protection Agency

Environmental Project No. 13412010

http://www2.mst.dk/udgiv/publications/2010/978-87-92708-00-7/pdf/978-87-92708-01-

$\underline{\text { 4.pdf }}$

Document was last accessed $16^{\text {th }}$ of February 2016

23W. Schafbauer, N. H. Menzler and H. P. Buchkremer, Tape Casting of Anode Supports

for Solid Oxide Fuel Cells at Forschungszentrum Jülich, Int. J. Appl. Ceram. Technol., 11 (2014), 125-135

24M. J. Cima, J. A. Lewis and A. D. Devoe, Binder distribution in Ceramic Greenware

During Thermolysis, J. Amer. Ceram. Soc., 72 ( 1989), 1192-1199 